\title{
Status of wild Bactrian camels and other large ungulates in south-western Mongolia
}

\author{
Richard P. Reading, Henry Mix, Badamjaviin Lhagvasuren and Evan S. Blumer
}

\begin{abstract}
Wild Bactrian camels Camelus bactrianus ferus are endangered. Surveys over the past several decades suggest a marked decline in camel numbers and reproductive success. However, most surveys were made using methods that precluded rigorous population estimation. The need for more accurate surveys resulted in an aerial survey of known and suspected camel habitat in Mongolia during March 1997. We estimated density, group density and population size of large mammals in south-western Mongolia using the interactive computer program DISTANCE. We recorded sufficient data for population modelling of wild Bactrian camels, goitred gazelles Gazella subgutturosa, Asian wild asses Equus hemionus and argali sheep Ovis ammon. We observed
\end{abstract}

277 camels in 27 groups (mean group size $=10.26 \pm$ 2.38 SE camels/group). Modelling yielded a population estimate of $1985 \pm 802$ SE camels in the survey area. Population modelling for other ungulates yielded estimates of $6046 \pm 1398$ SE goitred gazelles, $1674 \pm 506$ SE Asian wild asses and $909 \pm 303$ SE argalis. Discrepancies between population estimates of ungulates in our survey and previous surveys are discussed with regard to methods used and robustness of results obtained. We also discuss conservation implications for wild Bactrian camels and other Mongolian ungulates.

Keywords Argali, Asian wild ass, Bactrian camels, Camelus bactrianus, goitred gazelle, Mongolia.

\section{Introduction}

Status and distribution of ungulates in south-western Mongolia

South-western Mongolia is one of the most remote regions on Earth, with a very sparse human population. The region forms part of the larger Gobi Desert, which straddles the boundaries of China and Mongolia (Fig. 1) in Central Asia. The Gobi is a high altitude (700$1100 \mathrm{~m}$ ), cold desert characterized by dry stream beds, hummocks, rocky outcrops and mountain massifs (Zhirnov \& Ilyinsky, 1986). Because it remains remote and undeveloped, south-western Mongolia supports populations of several globally threatened and endangered species, including several large ungulates.

The wild subspecies of Bactrian camel Camelus bactri-

Richard P. Reading (corresponding author) Denver Zoological Foundation and Northern Rockies Conservation Cooperative, 2900 East 23rd Ave., Denver, CO 80205, USA. Fax: + 1303376 4901; e-mail: zooresearch@denverzoo.org

Henry Mix Nature Conservation International, Reinhardstrasse 10 , D-10117 Berlin, Germany.

Badamjaviin Lhagvasuren Mongolian Academy of Sciences, Institute of Biology, Ulaanbaatar-51, Mongolia.

Evan S. Blumer the Wilds, 14000 International Rd, Cumberland, $\mathrm{OH}$ 43732, USA.

Received 8 April 1998. Accepted 12 February 1999 anus ferus is the most endangered of the ungulates inhabiting the south-western Gobi Desert in Mongolia. Conservationists have become increasingly concerned about the status of wild camels (Yongzu, 1991; Tolgat \& Schaller, 1992; Wang \& Schaller, 1996; Hare, 1997). The decline of the species was first noted decades ago and was an important factor associated with the establishment of Region A of Great Gobi Strict Protected Area in 1975 (Fig. 2; Zhirnov \& Ilyinsky, 1986). Region B of the park was primarily established to protect Asian wild asses Equus hemionus. The $\sim 55,000-\mathrm{sq}-\mathrm{km}$ Great Gobi, as a strict protected area, excludes all human use, except for research, law enforcement and national border protection. This legislation, coupled with strict enforcement and the harsh Gobi environment, resulted in strong protection for the camel population and its habitat in Mongolia over the past 25 years. Although best known for its population of wild camels, Region A of Great Gobi harbours important populations of several large ungulates.

\section{Wild Bactrian camels}

Wild Bactrian camels are listed as Endangered by the World Conservation Union (IUCN, 1996) and in the Mongolian Red Book (Shiirevdamba et al., 1997). They are also protected in China and in Mongolia under the Mongolian Hunting Law (Wingard, 1996). Although domestic Bactrian camels range from Asia Minor through Central Asia to China and Mongolia, wild camels are restricted to three small, remnant popu- 
lations in China and Mongolia: in the Taklimakan Desert, the deserts around Lop Nur, and the area in and around Region A of Mongolia's Great Gobi Strict Protected Area (Fig. 1; Yongzu, 1991; Hare, 1997, 1998; Schaller, 1998). There is a small semi-captive herd of wild camels being maintained and bred outside Great Gobi Park near Bayantoori, Gobi-Altai Aimag (Fig. 2; UNDP, 1994).

Wild Bactrian camels are poorly understood. Knowledge of the species is derived from only a few short studies and anecdotal information (Anon., 1988; Tolgat \& Schaller, 1992; Hare, 1997; Tolgat, 1995; Wang \& Schaller, 1996). Recent global population estimates suggest that fewer than 900 individuals survive in small portions of Mongolia and China (Tolgat \& Schaller, 1992; Tolgat, 1995; Wang \& Schaller, 1996; Hare, 1997, 1998), and appear to be declining. Sporadic surveys and research, especially that of the joint Soviet-Mongolian Gobi Scientific Expedition, provided a small amount of information on wild camels in Mongolia. These data suggested camel numbers were declining and camel recruitment was low (i.e. a small proportion of young were observed; Zhirnov \& Ilyinsky, 1986; Anon., 1988; Tolgat \& Schaller, 1992; Tolgat, 1995; Schaller, 1998). Researchers suggested that the wild camel population in Mongolia has been restricted to Region A of Great Gobi Park for the past several decades and was 400-
900 in the 1970s (Bannikov, 1976; Dash et al., 1977; Schaller, 1998), 480-800 in the 1980s (Zhirnov \& Ilyinsky, 1986; Tolgat \& Schaller, 1992), and 300-500 in the early 1990s (Tolgat, 1995; Wang \& Schaller, 1996; Hare, 1997).

\section{Asian wild ass}

Mongolia also represents one of the last strongholds for Asian wild asses, which are included in Appendix I of the Convention on International Trade of Endangered Species of Fauna and Flora (CITES) and listed as Vulnerable by the IUCN (1996). Asian wild asses are listed as a Rare species in the Mongolian Red Book (Shiirevdamba et al., 1997) and are protected by the Mongolian Hunting Law (Wingard, 1996).

The species is rare in adjacent areas of China, especially Inner Mongolia, where the population may be sustained only by migration from Mongolia (Wang \& Schaller, 1996). Substantially larger numbers have been located in the desert and semi-desert regions of southern Mongolia (Zhirnov \& Ilyinsky, 1986; Mix et al., 1995; Wang \& Schaller, 1996; Feh et al., in press). Other small populations of different subspecies of Asian wild ass survive in northern Iran, south-western India, and central Asia, especially Turkmenistan (Nowak, 1991). The Equid Specialist Group of the IUCN's Species Survival Commission estimates that these other popu-

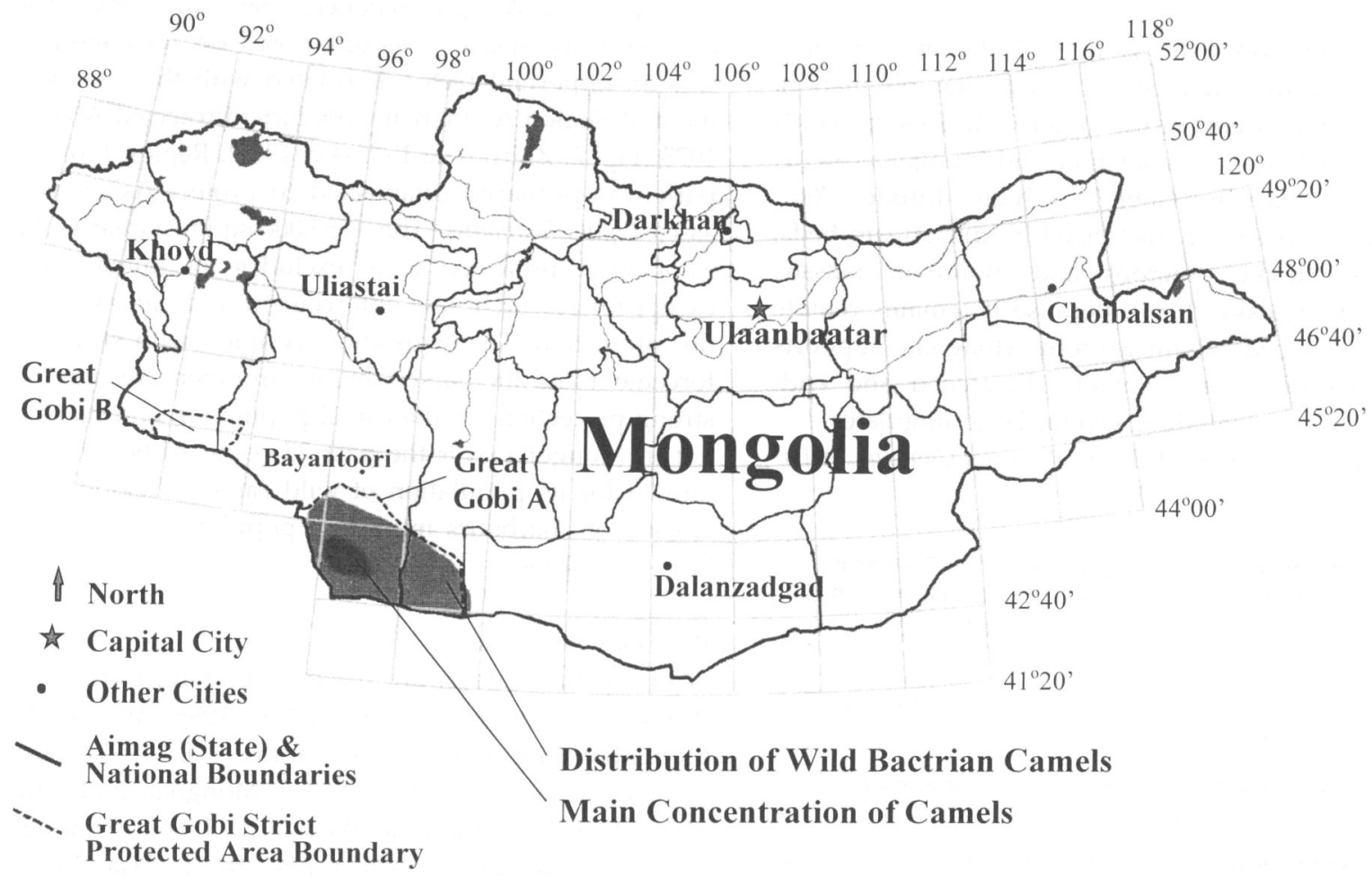

Fig. 1 Study site and the location of the main wild Bactrian camel concentration. The aerial survey of 2-6 March 1997 covered Region A of Great Gobi Strict Protected Area at $15 \mathrm{~km}$ intervals. 


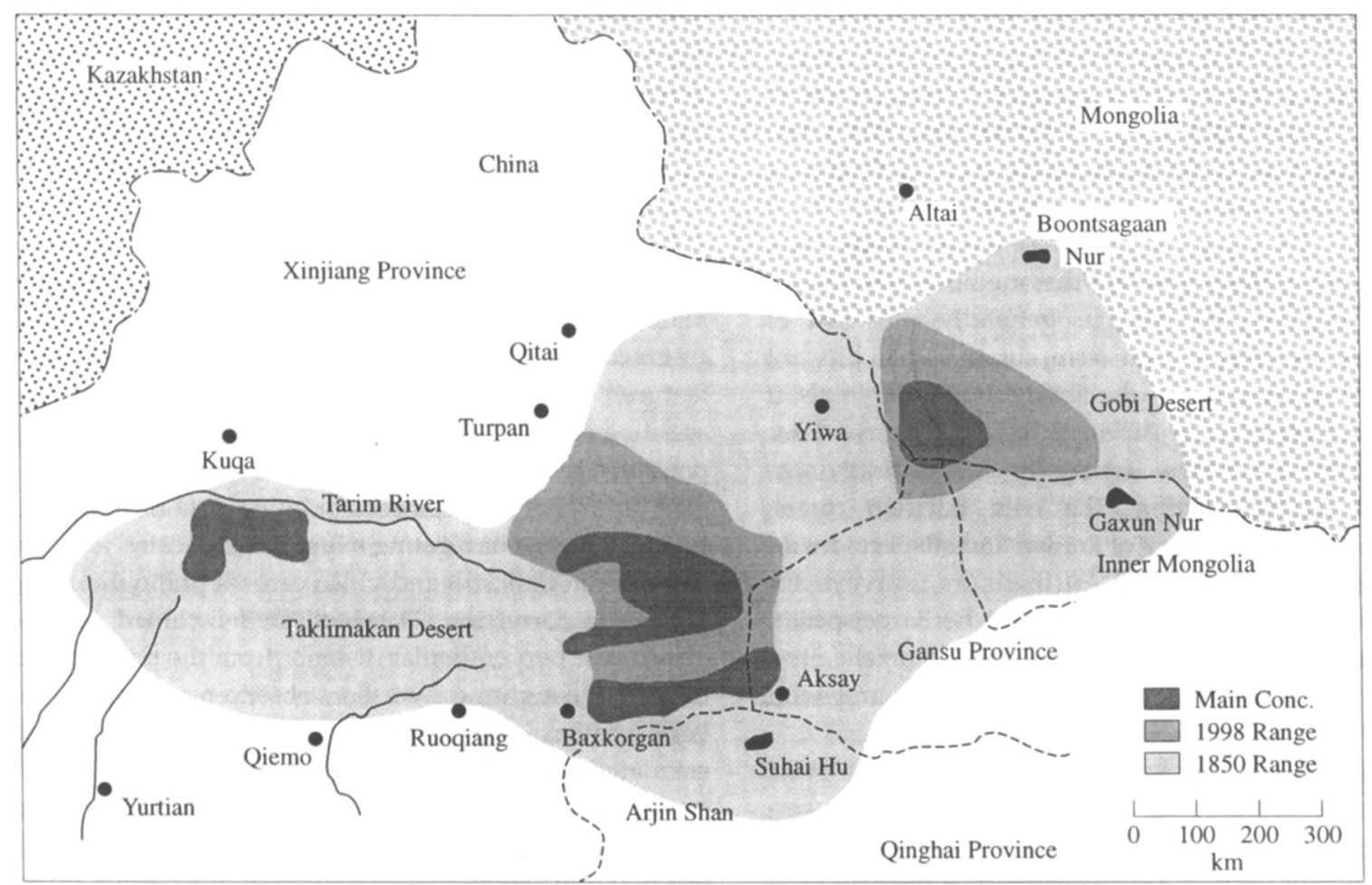

Fig. 2 Range reduction of wild Bactrian camels from 1850 to 1998. Adapted from Schaller (1998).

lations each contain fewer than 4000 animals, with most having far fewer (M. Rowen, pers. comm.).

\section{Goitred gazelle}

Goitred gazelles Gazella subgutturosa inhabit the arid and semi-arid regions of Mongolia and surrounding nations. In Mongolia, the species is primarily distributed in the southern third of the nation, having experienced a slight range retraction in the last few decades, especially in the Great Lakes region (Lhagvasuren et al., in press). The species is distributed through the 'desert and sub-desert steppes from Palestine and Arabian Peninsula to the Gobi Desert and northern China' (Nowak, 1991).

Goitred gazelles were listed as Vulnerable by the Soviet Union, are considered Near Threatened by the IUCN, and are listed as Rare in Mongolia, where the species is protected from hunting (Nowak, 1991; IUCN, 1996; Wingard, 1996; Shiirevdamba et al., 1997). Nevertheless, Mongolia may harbour the world's largest population of goitred gazelles (Zhirnov \& Ilyinsky, 1986; Nowak, 1991). Recent surveys in southern Mongolia support this assertion (Mix et al., 1995; Wang \& Schaller, 1996; H. Mix \& R. Reading, unpublished data).

\section{Argali}

Argali Ovis ammon are declining throughout Mongolia.
The species is listed as Rare in the Mongolian Red Book (Shiirevdamba et al., 1997), included in Appendix II of CITES, listed as Vulnerable by IUCN (1996), classified as Threatened on the USA's Endangered Species List (Nowak, 1993), and protected from general hunting in Mongolia (Wingard, 1996). Argali are distributed in the mountains and rocky outcrops of southern, central and western Mongolia, but the range of the species is decreasing and becoming increasingly fragmented (Mallon et al., 1997). The ranges of the Mongolian subspecies of argali (O. a. ammon and $O$. a. darwini) extend through adjacent regions of China, Kazakhstan and Russia, while other argali subspecies occur through the Pamir Mountains, Tian Shan Mountains, Kara Tau Mountains, Tibetan Plateau, and associated ranges of China, Afghanistan, Tajikistan, India, Nepal, and Kazakhstan (Shackleton, 1997; Schaller, 1998).

Poaching continues to be an important source of mortality for argali in Mongolia (Zhirnov \& Hlyinsky, 1986; Mallon et al., 1997; Reading et al., 1997; Shiirevdamba et al., 1997). Argali also suffer from competition for water and forage with domestic livestock, especially in the Altai Mountain regions (Sukhbat \& Gruzdev, 1986; Mallon et al., 1997; Reading et al., 1997; Shiirevdamba et al., 1997). 


\section{The need for surveys}

Most wildlife surveys carried out in Mongolia have been conducted using methods that preclude rigorous population estimation. Most of these surveys were neither systematic nor comprehensive, only surveying a small portion of the range of the populations they were targeting. In addition, when the methods used were revealed, population estimates generally consisted of simple extrapolations from strip surveys that did not incorporate differences in the ability to sight animals at varying distances or in different terrain. The need for more accurate surveys, especially for critically endangered species such as the wild Bactrian camel, prompted an aerial survey of known and suspected wild camel habitat in Mongolia. Furthermore, surveys for wild camels permit data collection on other large species of the Gobi, such as Asian wild ass, goitred gazelle, ibex Capra sibirica, argali, Gobi bear Ursus arctos and grey wolf Canis lupus.

The authors, working in close collaboration with other colleagues from Mongolia and the international conservation community, have initiated a wild Bactrian camel conservation programme in Mongolia. Systematic assessment of current status and reasons for decline are the crucial first steps. We conducted an aerial survey of camels and other large mammals of Region A of Great Gobi Park as part of the first step of this process.

\section{Study area}

The study area encompassed Region A of Great Gobi Strict Protected Area in the Mongolia Gobi Desert (Fig. 1 ). The region is characterized as a high upland (mean, $1300 \mathrm{~m}$ ) with dry stream beds, hummocks, rocky outcrops and mountain massifs rising to $2695 \mathrm{~m}$. Springs and other water sources are rare. The climate is strongly continental and arid, characterized by cold winters (to $-35^{\circ} \mathrm{C}$ ), dry, windy springs (to $50 \mathrm{mps}$ ), and relatively wet, hot summers (to $40^{\circ} \mathrm{C}$ ). Precipitation is low, averaging under $60 \mathrm{~mm} /$ year, with most precipitation falling in the summer months and some areas receiving no precipitation for years. Vegetation is sparse. Xerophytic and hyperxerophytic semi-shrubs, shrubs, scrub vegetation and turfy grasses dominate, including Haloxylon ammodendron, Sympegma ergelli, Anavasis brevifolia, Ephedra prjewaliskii, Ilynia regeli, Stipa glareosa, Stipa orientalis and Reumuria songarica. Other plant communities can be found around oases, on mountain massifs and other localized areas.

\section{Methods}

An aerial survey was conducted from 2-6 March 1997 over Region A of Great Gobi Strict Protected Area (Fig. 1). The survey was conducted by four non-Mongolian biologists, three Mongolian biologists and three protected-area staff members. We followed the guidelines proposed by Burnham et al. (1980) as modified by Reading et al. (1997) for conducting line transect surveys. A Soviet AN-2 biplane flew north-south, parallel transects separated by approximately $15 \mathrm{~km}$ at approximately $100 \mathrm{~m}$ above the ground. Navigation was conducted using compass bearings and landscape features. One Mongolian biologist was responsible for assisting the two pilots in accurate navigation. To compensate for the relatively fast air speed (mean, $170 \mathrm{~km} / \mathrm{h}$ ), four observers were placed on either side of the plane. In addition, the navigating expert often located animals. One person took still and video camera photographs for later data correction. Data collected included species, group size, perpendicular distance from the transect line, time of the sighting, weather, observer and the observer's location in the plane. Perpendicular distances were estimated by observers using markings on the wings as guides. Because we strove to fly at a constant height, markings on the wings indicated a known distance from the plane. In some cases, animals moved prior to detection, possibly introducing a source of bias into our estimate (Burnham et al., 1980). We conducted surveys from 09.12 to 11.40 hours and from 14.16 to 18.24 hours on 2 March, from 08.49 to 11.21 hours and from 13.39 to 15.39 hours on 3 March, and from 08.46 to 11.15 hours on 4 March, and between 09.54 and 12.50 hours on 6 March.

We estimated large mammal density, group density and population size using the interactive computer program DISTANCE (Laake et al., 1993). To obtain an estimate that accurately modelled the data, we pooled data into distance classes based on the distribution of sightings by distance for each species. These distance classes were: $0-100,101-250,251-500,501-1000,1001$ 2000 and $2001-3000 \mathrm{~m}$ for wild Bactrian camels; 0-100, $101-200,201-500,501-750,751-1000$ and 1001-2500 m for Asian wild asses; and 0-75, 76-150, 151-200, 201$400,401-500$ and $501-700 \mathrm{~m}$ for goitred gazelles. We allowed the program to select from a variety of possible estimators, including half-normal, negative exponential, hazard-rate, and uniform models based on minimum Akaike information criterion $(-2 * \ln$-likelihood $+2 m$, where $\mathrm{m}=$ the number of parameters; see Laake et al., 1993). We selected estimators whose probability detection function model was not significantly different from the distribution of actual observations using a chi-square goodness-of-fit test (Burnham et al., 1980, 1985; Buckland et al., 1993; Laake et al., 1993). For Bactrian camels only, we examined the robustness of our density and population estimates by excluding large portions of 
the survey area that did not have camel sightings (primarily in the north) and remodelling our data. Estimates using different survey areas and sampling effort varied by $<0.5$ per cent. Results are presented as \pm standard error (SE) of the mean.

\section{Results}

We flew $1700 \mathrm{~km}$ to survey $39,865 \mathrm{sq} \mathrm{km}$ of the region in and around Region A of Great Gobi Strict Protected Area in the south-south-western Gobi Desert (Fig. 1). During the survey we recorded 1033 individuals from seven species of mammals in 158 groups (Table 1). Sufficient data for population modelling were collected for only four large ungulates: wild Bactrian camels, goitred gazelles, Asian wild asses and argali.

Wild camels were the most commonly observed animals in the southern portion of the survey area. Overall, we observed 277 camels in 27 groups (Table 1). Mean group size was $10.26 \pm 2.38$ camels/group. Camels had a large flight distance, often running from the sound of the plane while still $>2 \mathrm{~km}$ away. Most camels were located somewhat west of the centre of Region A of Great Gobi Strict Protected Area-a desolate section of the Gobi Desert (Fig. 1). Modelling of the camel data yielded an animal density estimate of $4.98 \pm 2.01$ camels $/ 100 \mathrm{sq} \mathrm{km}$ (Table 2) and $1.17 \pm 0.38$ groups $/ 100 \mathrm{sq} \mathrm{km}$ in the survey area. This animal density estimate translates to a population estimate of 1985 camels (95\% confidence limits (CL) $=909-4335$ camels) in the surveyed area. Because virtually no camels exist outside the surveyed area, these results roughly estimate the total population of camels in Mongolia. Additional camels may reside in the border areas immediately adjacent to China, which we were unable to survey. Population estimates for all species should be viewed with caution because we observed fewer than the 40 groups recommended by the developers of the DISTANCE program (Burnham et al., 1980, 1985).

Asian wild asses were scattered throughout the surveyed area, but were slightly more numerous in the north. We observed 155 Asian wild asses in 36 groups, with a mean group size of $4.31 \pm 0.64$ animals/group (Table 1). Four groups were observed outside the surveyed area. We estimated Asian wild ass densities at $4.20 \pm 1.27$ animals $/ 100 \mathrm{sq} \mathrm{km}$ (Table 2) and $2.18 \pm 0.57$ groups $/ 100 \mathrm{sq} \mathrm{km}$. The population estimate for the surveyed area was therefore 1674 animals $(95 \% \mathrm{CL}=926-$ 3025 Asian wild asses).

Goitred gazelles were the most commonly observed animals during the aerial survey. We recorded 543 gazelles in 72 groups (Table 1), although most of these animals (38 groups) were observed to the north of the park while we were travelling to and from the surveyed area. Mean group size was $7.54 \pm 0.73$ animals/ group. Gazelles were concentrated in the northern portion of Great Gobi Park. Population modelling yielded estimates of $15.17 \pm 3.51$ animals $/ 100 \mathrm{sq} \mathrm{km}$ (Table 2) and $3.05 \pm 0.58$ groups $/ 100 \mathrm{sq} \mathrm{km}$. The population estimate for the surveyed area was therefore 6046 animals (95\% CL $=3826-9554$ gazelles).

In the mountainous areas we recorded 36 argali in 12 groups and 14 ibex in five groups (Table 1). Mean group sizes were $3.00 \pm 0.41$ animals/group for argali and $2.80 \pm 0.86$ animals/group for ibex. Both species were observed infrequently throughout the mountainous regions of the survey area. We were able to model the argali population. Argali density estimates were $2.28 \pm 0.76$ animals $/ 100 \mathrm{sq} \mathrm{km}$ (Table 2) and $0.81 \pm 0.24$ groups $/ 100 \mathrm{sq} \mathrm{km}$. The argali population estimate for the surveyed area was 909 animals (95\% CL $=441-1873$ argali).

We recorded data on two other species of mammals (Table 1). These included six grey wolves in four packs (mean size $=1.50 \pm 0.29$ wolves/group) and two lone red foxes Vulpes vulpes.

\section{Discussion}

\section{Wild camels}

Our estimated density of wild camels $(4.98 \pm 2.01$ camels $/ 100 \mathrm{sq} \mathrm{km}$ ) was within the 2.3-6.1 camels/ $100 \mathrm{sq} \mathrm{km}$ reported by Zhirnov \& Ilyinsky (1986) for

Table 1 Number of individuals, groups, and mean group size of species observed during an aerial survey of Region A of Great Gobi Strict Protected Area, 2-6 March 1997

\begin{tabular}{|c|c|c|c|c|}
\hline Species & No. of individuals & No. of groups & Mean group size & Range of group sizes \\
\hline Red fox Vulpes vulpes & 2 & 2 & 1.00 & 1 \\
\hline Grey wolf Canis Iupus & 6 & 4 & 1.50 & $1-2$ \\
\hline Goitred gazelle Gazella subgutturosa & 543 & 72 & 7.54 & $1-26$ \\
\hline Argali Ovis ammon & 36 & 12 & 3.00 & $1-5$ \\
\hline Ibex Capra sibirica & 14 & 5 & 2.80 & $1-6$ \\
\hline Asian wild ass Equus hemionus & 155 & 36 & 4.31 & $1-18$ \\
\hline Wild camel Camelus bactrianus & 277 & 27 & 10.26 & $1-55$ \\
\hline
\end{tabular}


Table 2 Large ungulate population density estimates ( \pm SE) for Region A of Great Gobi Strict Protected Area using the DISTANCE program

\begin{tabular}{lllll}
\hline Variable & Wild camel & Goitred gazelle & Asian wild ass & Argali \\
\hline Animal density (individuals $/ 100 \mathrm{sq} \mathrm{km})$ & $4.98 \pm 2.01$ & $15.17 \pm 3.51$ & $4.20 \pm 1.27$ & $2.28 \pm 0.76$ \\
Population estimate & $1985 \pm 802$ & $6046 \pm 1398$ & $1674 \pm 506$ & $909 \pm 303$ \\
Model & Hazard rate* & Hazard rate & Neg. Expon.t & Uniform $\ddagger$ \\
Significance§ & $P=0.44-0.49$ & $P=0.00-0.38$ & $P=0.92$ & $P=0.37-0.91$ \\
\hline
\end{tabular}

* Sightings modelled using the hazard rate key model: $k(y)=1-\exp \left(-(y / A(1))^{* *}-A(2)\right)$, where $k=$ the number of samples, $y=$ distance, and $A(i)=$ the $i$ th parameter in the estimated probability density function.

+Sightings modelled using the negative exponential model: $k(y)=\exp (-y / A(1))$, where $k=$ the number of samples, $y=$ distance, and $A(i)=$ the $i$ th parameter in the estimated probability density function.

† Sightings modelled using the uniform key model: $k(y)=1 / W$, where $k=$ the number of samples and $W=$ the width of the line transect. \$Significance measurements are for chi-square tests of actual data versus modelled curve. Better models have lower chi-square values, and thus higher $P$-values (i.e. actual data and modelled curves are not significantly different). Several $P$-values are provided for models which permitted data to be grouped into several different categories.

their aerial surveys in the early 1980s; however, our estimate of the total wild camel population (909-4335 animals) in Mongolia was larger than most previous estimates. Although Bannikov (1976) estimated 900 wild camels in 1974, other estimates in the 1970s and 1980s were 400-700 animals in 1976 (Dash et al., 1977), 500-800 animals in 1980-81 (Zhirnov \& Ilyinsky, 1986), and 480-555 animals between 1982 and 1989 (Tolgat \& Schaller, 1992). More recently, Wang \& Schaller (1996) estimated that $400-500$ camels occupied $28,000 \mathrm{sq} \mathrm{km}$ of Great Gobi Strict Protected Area in the early 1990s, Tolgat (1995) suggested that the Mongolian camel population dropped to $300-400$ animals by the early 1990s, and Hare (1997) suggested that only 350-400 camels survive in Mongolia.

Results from previous surveys of wild Bactrian camels are probably less reliable than this study because, first, none of the earlier studies systematically surveyed the entire range of wild camels and, second, previous estimates were based on simple extrapolations of camel sightings by ground expeditions or naive estimates based on aerial surveys. For example, previous surveys generally assumed equal sightability of animals at different distances from transect lines. However, visibility varies with distance and terrain. As a result, we would predict population estimates lower than those reported in this study. Nevertheless, because several of these past studies used consistent methods, the declining trends in camel numbers may be real. And although the results from this study suggest a larger population of wild camels than previously thought, the numbers are still relatively small and give cause for concern. Periodic, additional surveys with greater sampling effort are required to increase the sample size (i.e. number of groups observed) and reduce the wide confidence limits found here and to track population trends in the wild camel population.

Mean group size $(10.26 \pm 2.38$ camels/group, Table 1) was slightly larger than the 3.5-8.9 camels/group (no statistics of variance or range reported) reported by
Zhirnov \& Ilyinsky (1986) and the 6.0 camels/group ( $n=675$, range $=1-48$ ) reported by Schaller (1998). Little is known about wild camel ecology, but group size may well vary with season.

Most authors also report a small ratio of young to adults (Tolgat \& Schaller, 1992; Tolgat, 1995; Schaller, 1998), something we were unable to assess. The reasons for the reportedly low camel recruitment are unknown. Tolgat (1995) suggests that camel predation by wolves is high, although he bases his assessment simply on the presence of wolf sign near the majority (61-84 per cent) of camel carcasses discovered. Because it is not possible to distinguish between wolf kills and scavenging, the impact of wolves on the camel population is unclear. We observed only six wolves during our survey, suggesting that the population of wolves in the region may be small. Other suggested causes of decline include poaching, especially when camels move across the border and into China, and a decline in habitat quality. Extremely arid and sparsely vegetated, Great Gobi provides little forage in the best circumstances (Zhirnov \& Ilyinsky, 1986), and a recent prolonged drought has exacerbated this situation.

\section{Asian wild ass}

The density $(4.20 \pm 1.27$ animals $/ 100 \mathrm{sq} \mathrm{km})$ of Asian wild asses from this study was within the 0.8-5.1 animals/100 sq km range reported by Zhirnov \& Ilyinsky (1986) for aerial surveys conducted in Region A of Great Gobi Park in the early 1980 s. In other parts of Mongolia, Feh et al. (in press) found $16.06-17.72$ asses/100 sq km in Region B of Great Gobi and Reading et al. (unpublished data) found densities of $17.94 \pm 4.14-19.13 \pm 3.20$ asses/ $100 \mathrm{sq}$ km in the south-eastern Gobi.

The mean group size ( $4.31 \pm 0.64$ asses/group) found in this study was also similar to that reported for the species in Mongolia. An earlier study in Great Gobi A found group sizes of 1.7-7.0 animals/group (Zhirnov \& 
Ilyinsky, 1986). Reading et al. (unpublished data) found means of $4.50 \pm 1.19-7.00 \pm 2.49$ asses/group in the south-central Gobi and 3.41 $\pm 0.64-18.20 \pm 5.39$ asses/ group in the south-eastern Gobi of Mongolia. Feh et al. (in press) found a median group size of 6.25 asses in Region A of Great Gobi.

Both Zhirnov \& Ilyinsky (1986) and Feh et al. (in press) estimated that 800 Asian wild asses inhabited Great Gobi Strict Protected Area A, but methods by which numbers were estimated and descriptive statistics were lacking in both studies. In the last few decades, Asian wild asses have been reported as declining, being forced into more marginal habitats as a result of poaching and competition for forage and water (Zhirnov \& Ilyinsky, 1986). However, recent surveys suggest that the species is expanding into its former range (Mix et al., 1995; Feh et al., in press; Reading et al., unpublished data).

\section{Goitred gazelle}

There is little published research on goitred gazelle in Mongolia. We found higher densities (15.17 \pm 3.51 animals $/ 100 \mathrm{sq} \mathrm{km}$ ) and numbers (3826-9554) of goitred gazelles than previously reported for the region, but mean group size ( $7.54 \pm 0.73$ gazelle/group) was within the reported ranges. Zhirnov \& Ilyinsky (1986) reviewed the findings of Russian researchers in the 1970 s who estimated goitred gazelle population sizes of 5500-13,000 animals for all of Mongolia. More recent aerial surveys in Great Gobi Strict Protected Area A found mean densities of $0.8-3.6$ gazelle/100 sq $\mathrm{km}$ and mean group sizes of 2.3-8.5 gazelle/group (Zhirnov \& Ilyinsky, 1986). Extrapolation yielded estimates of 800-1000 for Gobi A, although the methods used to determine these numbers were not provided.

Reading et al. (unpublished data) found much higher densities of goitred gazelle $(74.58 \pm 10.96-97.99 \pm 23.10$ gazelle $/ 100 \mathrm{sq} \mathrm{km}$ ) for the south-central Gobi. Mean group sizes varied from 3.73 to 12.07 animals/group, and were a very similar 7.81 gazelles/group at the same time of year (i.e. early March 1997) in this study (Reading et al., in press). Wang \& Schaller (1996) observed only 32 goitred gazelle over $7850 \mathrm{~km}$ of driving in Inner Mongolia, but $>1600$ gazelle over $2700 \mathrm{~km}$ in Mongolia.

\section{Argali}

The mean argali group size ( $3.00 \pm 0.41$ animals/group) was slightly smaller than group sizes found in other studies. Mean group sizes of argali from other studies throughout Mongolia range from 3.5 to 13.8 animals/ group (see discussion in Reading et al., 1997).
Argali density $(2.28 \pm 0.76$ animals $/ 100 \mathrm{sq} \mathrm{km})$ was similar to the $1.9 \pm 0.5$ argali $/ 100 \mathrm{sq} \mathrm{km}$ reported by Reading et al. (1997) for an aerial survey of the southcentral Gobi. Although densities estimated from aerial surveys and ground surveys are not directly comparable because aerial surveys cover a substantial amount of unsuitable habitat, reported densities from ground surveys of argali in trans-Altai Mongolia lie between 0.2 and 8.0 animals/100 sq km (Sukhbat \& Gruzdev, 1986; Zhirnov \& Ilyinsky, 1986). Argali densities are substantially greater in other parts of the country (see Reading et al., 1997).

\section{Conservation implications}

The large ungulates of the Gobi Desert require substantial additional conservation and research attention. Our results suggest that previous population estimates may be underestimating population sizes of some species. While this is positive news from a conservation perspective, it does not negate the importance of additional conservation and research efforts. It does mean there is time for longer, more detailed ecological studies. Such studies should be conducted throughout the year to assess population dynamics and trends, critical habitats and movement patterns as a basis for developing conservation management and recovery plans. For declining species, such as the wild Bactrian camel, understanding the causes of decline is crucial to the development of effective conservation programmes.

Mongolian and Chinese conservationists must begin co-ordinating conservation activities for species that range across the border between the two countries. This is especially true for the endangered wild camel. Because of their expansive habitat requirements, understanding camel population dynamics and ecological requirements may lead to camel conservation programmes that effectively conserve many of the species of the Gobi Desert.

Mongolia is currently undergoing the difficult transition from a communist government with a centrally controlled economy to a democracy with a free market (UNDP, 1997). This transition provides some of the greatest challenges and greatest opportunities for conservation of the nation's natural resources. Thus far, the transition in Mongolia has been relatively smooth but high inflation has reduced the ability of the government to maintain key conservation programmes and staff. In addition, Mongolia's isolation from the West prevented acquisition of knowledge and training in new developments in ecology and conservation biology. These needs are being partially met by international donor agencies and projects. 
Mongolia's centuries-old tradition of respect and sense of responsibility toward nature helps maintain a government committed to conservation. The Mongolian government recently passed a resolution targeting placement of 30 per cent of its land under some form of protection. A supportive atmosphere, therefore, exists for conservation activities in Mongolia. However, as both internal and external pressures for development and natural resources exploitation grow, the number of challenges facing conservation increases. The data presented here and in other recent studies (Mix et al., 1995; Mallon et al., 1997; Reading et al., 1997; Reading et al., in press; unpublished data; Schaller, 1998; Feh et al., in press; Lhagvasuren et al., in press) suggest that Mongolia has some of the largest populations of many large ungulates species in Central Asia. As such, Mongolia has the opportunity to be proactive in the conservation of several of its species and much of its environment, but Mongolian conservationists and their international collaborators must work rapidly to create the necessary support, capacity and infrastructure for effective conservation.

\section{Acknowledgements}

Funding for this project was provided by Nature Conservation International, the Chicago Zoological Society, the Denver Zoological Foundation, the Wilds, and the Mongolian Academy of Sciences. Amgalan, Choijun, Z. Namshir and Mijidorj assisted with data collection. We thank T. Galbaatar, J. Wingard, J. Wortman and the staff of the Great Gobi Strict Protected Area for their assistance with various portions of this study. J. Berger, G. Meffe, $B$. Miller and three anonymous reviewers provided valuable comments that helped strengthen the manuscript.

\section{References}

Anon. (1988) Great Gobi National Park Management Plan. 2 Vols. United Nations Environment Programme, Ulaanbaatar, Mongolia.

Bannikov, A. (1976) The wild camels of the Gobi. Wildlife, 18, 398-403.

Buckland, S.T., Anderson, D.R., Burnham, K.P. \& Laake, J.L. (1993) Distance Sampling: Estimating Abundance of Biological Populations. Chapman and Hall, London.

Burnham, K.P., Anderson, D.R. \& Laake, J.L. (1980) Estimation of density from line transect sampling of biological populations. Wildife Monographs, 72, 1-202.

Burnham, K.P., Anderson, D.R. \& Laake, J.L. (1985) Efficiency and bias in strip and line transect sampling. Journal of Wildlife Management, 49, 1012-1018.

Dash, Y, Szaniawski, A., Child, G. \& Hunkeler, P. (1977) Observations on some large mammals of the Transaltai, Djungarian, and Shargin Gobi, Mongolia. Terre et Vie, 31, 587-596.
Feh, C., Munkhtuya, B., Enkhbold, S., Avirmed, A. \& Sukhbaatar, T. (in press) Status, distribution, ecology and social structure of the Gobi khulan (Equus hemionus subspp) in Mongolia. Biological Conservation.

Hare, J. (1997) The wild Bactrian camel Camelus bactrianus ferus in China: the need for urgent action. Oryx, 31, $45-48$.

Hare, J. (1998) The Lost Camels of Tartary: A Quest into Forbidden China. Little, Brown and Company, London.

IUCN (1996) 1996 IUCN Red List of Threatened Animals. IUCN, Gland, Switzerland.

Laake, J.L., Buckland, S.T., Anderson, D.R. \& Burnham, K.P. (1993) Distance User's Guide V2.0. Colorado Cooperative Fish and Wildlife Research Unit. Colorado State University, Fort Collins, CO.

Lhagvasuren, B., Dulamtseren, S. \& Amgalan (in press) Status and distribution of antelope species in Mongolia. In Antelopes: Global Survey and Action Plan. Part 4. Eurasia. IUCN, Gland, Switzerland.

Mallon, D.P., Dulamtseren, S., Bold, A., Reading, R.P. \& Amgalanbaatar, S. (1997) Mongolia. In Wild Sheep and Goats and Their Relatives: Status Survey and Conservation Action Plan for Caprinae (ed. D. M. Shackleton), pp. 193-201. IUCN, Gland, Switzerland.

Mix, H., Reading, R.P. \& Lhagvasuren, B. (1995) A systematic census of various large mammals in Eastern and Southern Mongolia. In Proceedings from the Conference on Asian Ecosystems and Their Protection, August 1995. Ulaanbaatar, Mongolia (in Russian).

Nowak, R.M. (1991) Walker's Mammals of the World, vol. II, 5 th edn. The Johns Hopkins University Press, Baltimore, Maryland.

Nowak, R. (1993) Court upholds controls on imports of argali trophies. Endangered Species Technical Bulletin, 18(4), $11-12$.

Reading, R.P., Amgalanbaatar, S., Mix, H. \& Lhagvasuren, B. (1997) Argali Ovis ammon surveys in Mongolia's South Gobi. Oryx, 31, 285-294.

Reading, R.P., Amgalanbaatar, S. \& Lhagvasuren, L. (in press) Biological assessment of Three Beauties of the Gobi National Conservation Park, Mongolia. Biodiversity and Conservation.

Schaller, G.B. (1998) Wildlife of the Tibetan Steppe. University of Chicago Press, Chicago, Illinois.

Shackleton, D. (ed.) (1997) Wild Sheep and Goats and Their Relatives: Status Survey and Conservation Action Plan for Caprinae. IUCN, Gland, Switzerland.

Shiirevdamba, Ts., Shagdarsuren, O., Erdenjav, G., Amgalan, Ts. \& Tsetsegma, Ts. (eds) (1997) Mongolian Red Book. Ministry for Nature and the Environment of Mongolia, Ulaanbaatar, Mongolia (in Mongolian, with English summaries).

Sukhbat, Kh. \& Gruzdev, V.B. (1986) The mountain sheep argali in the Mongolian People's Republic. In Natural Conditions and Biological Resources of the Mongolian People's Republic, pp. 195. Moscow (in Russian).

Tolgat, R. (1995) Results of wild Bactrian camel (Camelus ferus Prz.) surveys and their biological meaning. In Proceedings from a Conference on the Biology and Nature of Great Gobi Strict Protected Area, 12 June 1995 (ed. J. Badamkhand), pp. 87-90. Ministry for Nature and the Environment, Ulaanbaatar, Mongolia (in Mongolian). 
Tolgat, R. \& Schaller, G. (1992) Status and distribution of wild Bactrian camels. Biological Conservation, 62, 11-19.

UNDP (1994) Mongolia Biodiversity Project-Implementation Phase Document. UNDP, Ulaanbaatar, Mongolia.

UNDP (1997) Human Development Report: Mongolia 1997. Government of Mongolia and United Nations Development Programme, Ulaanbaatar, Mongolia.

Wang, X. \& Schaller, G.B. (1996) Status of large mammals in western Inner Mongolia, China. Journal of East China Normal University (Natural Science), 12, 93-104.

Wingard, J.R. (1996) Mongolian Environmental Law: Reference Copy for Biodiversity Project Staff. Mongolia Biodiversity Project, Ministry for Nature and the Environment, Ulaanbaatar, Mongolia.

Yongzu, Z. (1991) Mammalian zoogeography and conservation of the endangered species in arid areas of China. In Mammals of the Palaearctic Desert: Status and Trends in the Saharan-Gobin Region (eds J. A. McNeely and V. M. Neronov), pp. 269-284. The Russian Academy of Sciences and The Russian Committee for the UNESCO Programme on Man and the Biosphere, Moscow.

Zhirnov, L.V. \& Ilyinsky, V.O. (1986) The Great Gobi Reserve - a Refuge for Rare Animals of the Central Asian Deserts. USSR/UNEP Project, Programme for Publication and Informational Support. Centre for International Projects, GKNT, Moscow.

\section{Biographical sketches}

Dr Rich Reading is the Director of Conservation Biology at the Denver Zoological Foundation and an Associate Research Professor at the University of Denver in Colorado, USA. He is interested in developing interdisciplinary approaches to conservation challenges and has worked on a variety of conservation issues in Mongolia since 1994.

Dr Henry M. Mix is president of Nature Conservation International, a non-profit organization based in Berlin, Germany, and has been working on conservation and management in Mongolia for over 10 years.

Badamjaviin Lhagvasuren is a biologist with the Biology Institute of the Mongolian Academy of Sciences and President of the Society for the Conservation of Mongolian Gazelle. His research focuses on the ecology of Mongolia's large ungulates.

Dr Evan Blumer is the Deputy Director of the Wilds animal park in Ohio, USA, and an active wildlife veterinarian. 